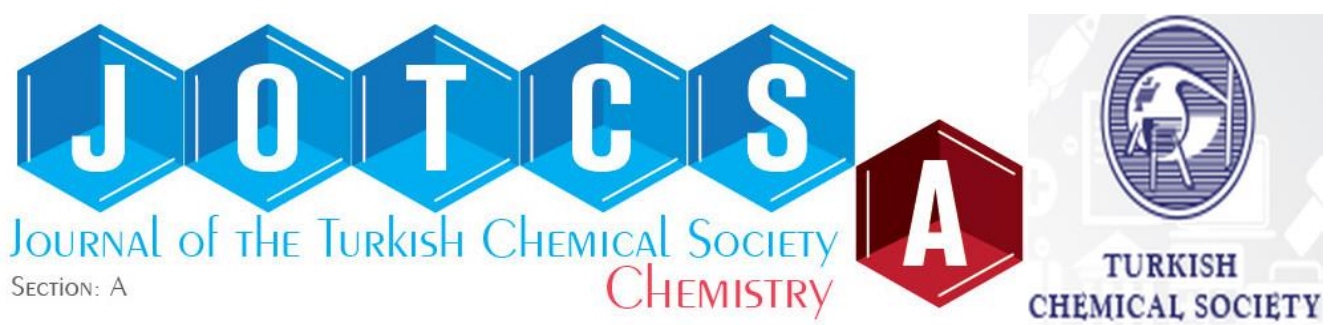

\title{
Synthesis and Characterization of Polysulfone-based Graft Copolymers Possessing Quaternary Ammonium Salts via Photoiniferter Polymerization
}

\author{
Serhat Oran ${ }^{1}$, Mehmet Atilla Tasdelen ${ }^{1 *}$ \\ ${ }^{1}$ Department of Polymer Engineering, Faculty of Engineering, Yalova University, 77100, Yalova, \\ Turkey
}

\begin{abstract}
Well-defined polysulfone-based graft copolymers containing quaternary ammonium salts were successfully prepared by photoiniferter method under mild conditions (at room temperature and nitrogen atmosphere). The corresponding macroiniferter agent was sequentially synthesized by chloromethylation and nucleophilic substitution reactions between obtained chloromethylated polysulfone and sodium diethyldithiocarbamate. Upon UV irradiation, this macroiniferter enabled the accomplished grafting of 2-(dimethylamino) ethyl methacrylate onto the polysulfone backbone in a controlled manner. After the successful synthesis of graft copolymers, the tertiary amine groups in the side-chains are readily quaternized using methyl iodide to get desired quaternary ammonium salts containing graft copolymers.
\end{abstract}

Keywords: Graft copolymer; iniferter; polysulfone; photopolymerization; quarternary ammonium salts.

Submitted: October 25, 2017. Accepted: November 19, 2017.

Cite this: Oran S, Taşdelen M. Synthesis and Characterization of Polysulfone-based Graft Copolymers Possessing Quaternary Ammonium Salts via Photoiniferter Polymerization. JOTCSA. 2018;5(1):117-32.

DOI: http://dx.doi.org/10.18596/jotcsa.346590.

Corresponding author. E-mail: tasdelen@yalova.edu.tr 


\section{INTRODUCTION}

Polysulfones (PSU) are the family of thermoplastics that have excellent thermal and chemical stability, high radiation degradation resistance, transparency, high rigidity, mechanical strength, and good electrical and film properties $(1,2)$. To benefit from above-mentioned advantages, they have been used in many applications such as medical devices (hemodialysis), food processing, feeding systems, automotive, electronics, water distillation, gas separation, and fuel cells (3-5). However, these PSU have some drawbacks including stress cracking with certain solvents, poor tracking resistance, and weathering properties. To overcome these limitations and also extend their potential applications, the functionalization of PSU is a subject of considerable interest in recent studies (6, 7). There are two main functionalization methods; (i) functional monomer and (ii) postfunctionalization approaches (8). The post-functionalization is most widely applied method in which the desired functionality is attached onto the polymer end- or side-chains of polymers $(9,10)$. The chemical structure of PSU backbone contains two different repeating units, electron-deficient phenyl sulfone and electron-rich bisphenol A groups that are suitable both electrophilic and nucleophilic substitution reactions for the incorporation of various functional groups. For example, sulfonation, chloromethylation, lithiation, and other methods are successfully applied for the side-chain functionalization of PSU in the literature (9). The grafting method including polymer chains with different chemical natures are attached onto another polymer backbone is a versatile process for the functionalization of polysulfones (11-16). The resulting functional polysulfone graft copolymers exhibit superior properties such as high porosity, wettability, and protein resistance compared to the non-functionalized polysulfones.

The iniferter (initiator-transfer-terminator agent) polymerization is the first controlled radical polymerization method discovered by Otsu and co-workers (17-19). In this method, the radical polymerization proceeds in a controlled manner where "active" and "dormant" propagating chain ends are reversibly equilibrated throughout the polymerization period (20-22). Various macromolecular architectures including telechelic $(23,24)$ and hyper-branched polymers $(25,26)$ and also block (27-31) and graft (32) copolymers can be simply synthesized under mild conditions via thermal or photochemical activations. $(33,34)$

In this study, firstly, commercially available polysulfone was chloromethylated by a well-known 
procedure using paraformaldehyde, trimethylsilyl chloride, and tin (IV) chloride. Then, the obtained polymers were converted to the macroiniferter by changing chloromethyl moieties with diethyl dithiocarbamate groups via nucleophilic substitution reaction. By applying UV irradiation, this macroiniferter (side-chain functional diethyl dithiocarbamate polysulfone) were enabled to conduct the radical polymerization of 2-(dimethylamino) ethyl methacrylate in a controlled manner. As a result of the iniferter polymerization, a well-defined graft copolymer (polysulfone- $g$-poly(2(dimethylamino)ethyl methacrylate)) was successfully synthesized under mild conditions, i.e., UV irradiation and room temperature. Finally, quaternization experiment using methyl iodide was applied to obtain desired polysulfone graft copolymer containing quaternary ammonium salts. The structures and properties of intermediate and final products were characterized by various techniques including spectroscopic (FT-IR and ${ }^{1} \mathrm{H}-\mathrm{NMR}$ ), chromatographic (GPC), and thermal (DSC) analysis.

\section{MATERIALS AND METHODS}

\section{Materials}

Polysulfone (Udel $®$ P-1700, Solvay), paraformaldehyde (95\%, Merck), tin(IV) chloride (98\%, Alfa Aesar), trimethylsilyl chloride ( $\geq 99.0 \%$, Aldrich), sodium azide (99\%, Merck), sodium diethyldithiocarbamate (BDH Chem.) 2-(dimethylamino)ethyl methacrylate (99\%, Merck) and methyl iodide (Aldrich) were used as received. Commercial grade solvents $N, N$-dimethylformamide ( $\geq 99.8 \%$, Merck), chloroform ( $\geq 99.8 \%$, Merck), pyridine ( $\geq 99.0 \%$, Aldrich), dimethyl sulfoxide (VWR) tetrahydrofuran ( $\geq 99.7 \%, \mathrm{VWR}$ ) and methanol (100\%, VWR) were purchased and used as received.

\section{Chloromethylation of polysulfones}

Polysulfone $(20 \mathrm{~g}, 0.5 \mathrm{mmol})$ was dissolved with chloroform ( $600 \mathrm{~mL}$ ) in a $1000 \mathrm{~mL}$ glass flask by using ultrasonic bath and then paraformaldehyde $(57 \mathrm{~mL}, 450 \mathrm{mmol}$ ) and trimethylsilyl chloride (57 $\mathrm{mL}, 450 \mathrm{mmol}$ ) were added carefully into the mixture (13). After the mixture was stirred for a while, tin(IV) chloride $(0.52 \mathrm{~mL}, 4.5 \mathrm{mmol})$ was added into this solution and the mixture was stirred at room temperature for 72 hours. All these steps and the reaction were carried out under inert atmosphere. End of the given time, the product was precipitated into excess methanol. Then, the precipitate was filtered and dried in a vacuum oven at room temperature. 
In order to confirm the successful of the chloromethylation process by FT-IR spectroscopy, the chloromethyl groups were converted to azide groups having characteristic band at $2150 \mathrm{~cm}^{-1}$. For this purpose, the chloromethylated polysulfone $\left(\mathrm{PSU}-\mathrm{CH}_{2}-\mathrm{Cl}\right)(1 \mathrm{~g}, 0.026 \mathrm{mmol})$ was dissolved in $20 \mathrm{~mL}$ of dimethylformamide (DMF) and sodium azide $\left(\mathrm{NaN}_{3}\right)(100 \mathrm{mg}, 1.54 \mathrm{mmol})$ was added into the solution. The mixture flask was wrapped up with alumina film to protect from solar light and then the mixture was stirred at $50{ }^{\circ} \mathrm{C}$ for $24 \mathrm{~h}$. Finally, the product was precipitated into excess methanol, filtered, and dried in a vacuum oven at room temperature.

\section{Synthesis of polysulfone-based macroiniferter (PSU-DDC)}

Iniferter functionalized polysulfone (PSU-DDC) was synthesized from the reaction of PSU with sodium diethyldithiocarbomate (35). The $\mathrm{PSU}-\mathrm{CH}_{2}-\mathrm{Cl}$ (500 mg, $0.013 \mathrm{mmol}$ ), sodium diethyldithiocarbamate $(60 \mathrm{mg}, 0.35 \mathrm{mmol})$ and pyridine $(5 \mathrm{~mL})$ were placed to a $100 \mathrm{~mL}$ flask. After mixing and dissolution processes had been finished, the mixture flask was stirred in silicon oil bath at room temperature for $24 \mathrm{~h}$. The solution was precipitated into methanol, filtered, and dried in a vacuum oven.

\section{Synthesis of polysulfone-g-poly(2-(dimethylamino)ethyl methacrylate) (PSU-g- PDMAEMA) via photoiniferter polymerization}

PSU-DDC (50 mg, $0.0013 \mathrm{mmol}$ ) and DMF (1 mL, $0.013 \mathrm{mmol}$ ) were placed into a tube. After PSUDDC completely dissolved, 2-(dimethylamino)ethyl methacrylate (DMAEMA) (1 mL, $5.94 \mathrm{mmol}$ ) was added into the solution tube and nitrogen was bubbled through 2-3 minutes. Then, the tube was irradiated by a UV photoreactor within 300-400 nm wavelength (Philips TL-D 18W) at room temperature for different reaction times. The solution mixture was precipitated into excess amount of hexane and then filtered. The product was dried under vacuum.

\section{Quarternarization of PSU-g-PDMAEMA}

PSU-g-PDMAEMA (165 mg, $0.003 \mathrm{mmol})$ and THF ( $5 \mathrm{~mL}, 0.07 \mathrm{mmol}$ ) were added into a flask. After the polymer was completely dissolved, methyl iodide ( $\mathrm{CH} 3 \mathrm{I})(50 \mu \mathrm{L}, 0.0008 \mathrm{mmol})$ was carefully added into the solution flask and the mixture was stirred in silicon oil bath at room temperature for $24 \mathrm{~h}$. The mixture was precipitated in hexane and filtered. After filtration, polymers were dried for 24 hours in a vacuum oven. 


\section{Analysis}

A Perkin-Elmer FT-IR Spectrum One B spectrometer was used for FT-IR analysis. The Agilent NMR System VNMRS 500 spectrometer was used at room temperature in $\mathrm{CDCl}_{3}$ with $\mathrm{Si}\left(\mathrm{CH}_{3}\right)_{4}$ as an internal standard for ${ }^{1} \mathrm{H}-\mathrm{NMR}$ analysis. Molecular weights were determined by a Viscotek GPCmax Autosampler system consisting of a pump module (GPCmax, Viscotek, Houston, TX), a combined light-scattering (Model 270 dual detector, Viscotek), and a refractive index (RI) detector (VE 3580, Viscotek). The light-scattering detector $\left(\lambda_{0}=670 \mathrm{~nm}\right)$ included two scattering angles: 7 and $90^{\circ}$. The RI detector was calibrated with polystyrene standards having narrow molecular weight distribution, and hence the quoted molecular weights of the polymers were expressed in terms of polystyrene equivalents. Two columns ( 7.8 × 300 mm, LT5000L, Mixed, Medium Org and LT3000L, Mixed, UltraLow Org) with a guard column ( $4.6 \times 10 \mathrm{~mm}$, Viscotek, TGuard) were used for the chloroform eluent at $35{ }^{\circ} \mathrm{C}$ (flow rate, $1 \mathrm{~mL} / \mathrm{min}$ ). Data were analyzed using Viscotek OmniSEC Omni-01 software. Differential scanning calorimetry (DSC) was performed on a Perkin-Elmer Diamond DSC with a heating rate of $10^{\circ} \mathrm{C} / \mathrm{min}$ under nitrogen flow $(10 \mathrm{~mL} / \mathrm{min})$.

\section{RESULTS AND DISCUSSIONS}

There are three main methods for the synthesis of graft copolymers; (i) grafting-onto, (ii) graftingfrom and (iii) grafting-through (macromonomers) (36-39). Among them, grafting-from approach is a very useful method since a wide range of monomers can be used together with different reaction conditions (40). In this method, an initiator is attached onto the polymer backbone and subsequent polymerization of second monomer enables to form corresponding graft copolymers. In our case, firstly, iniferter (diethyl dithiocarbamate) group was attached onto PSU backbone by sequantial chloromethylation and nucleophilic substitution reactions. The chloromethylated polysulfone was synthesized according to the well-known procedure (13). Then, its structure was confirmed by FTIR and ${ }^{1} \mathrm{H}-\mathrm{NMR}$ techniques in accordance with respect to the literature data $(11,15)$. Due to overlapping of chloromethyl bands with the characteristic polysulfone bands, determination of chloromethylation was difficult with FT-IR spectroscopy. Therefore, the chlorine atoms were replaced with azide groups that were easily detectable in FT-IR spectroscopy. The characteristic azide band at $2250 \mathrm{~cm}^{-1}$ was obviously detected in FT-IR spectrum (Figure 1). Thus, the successful chloromethylation of PSU was proven by FT-IR spectroscopy. 


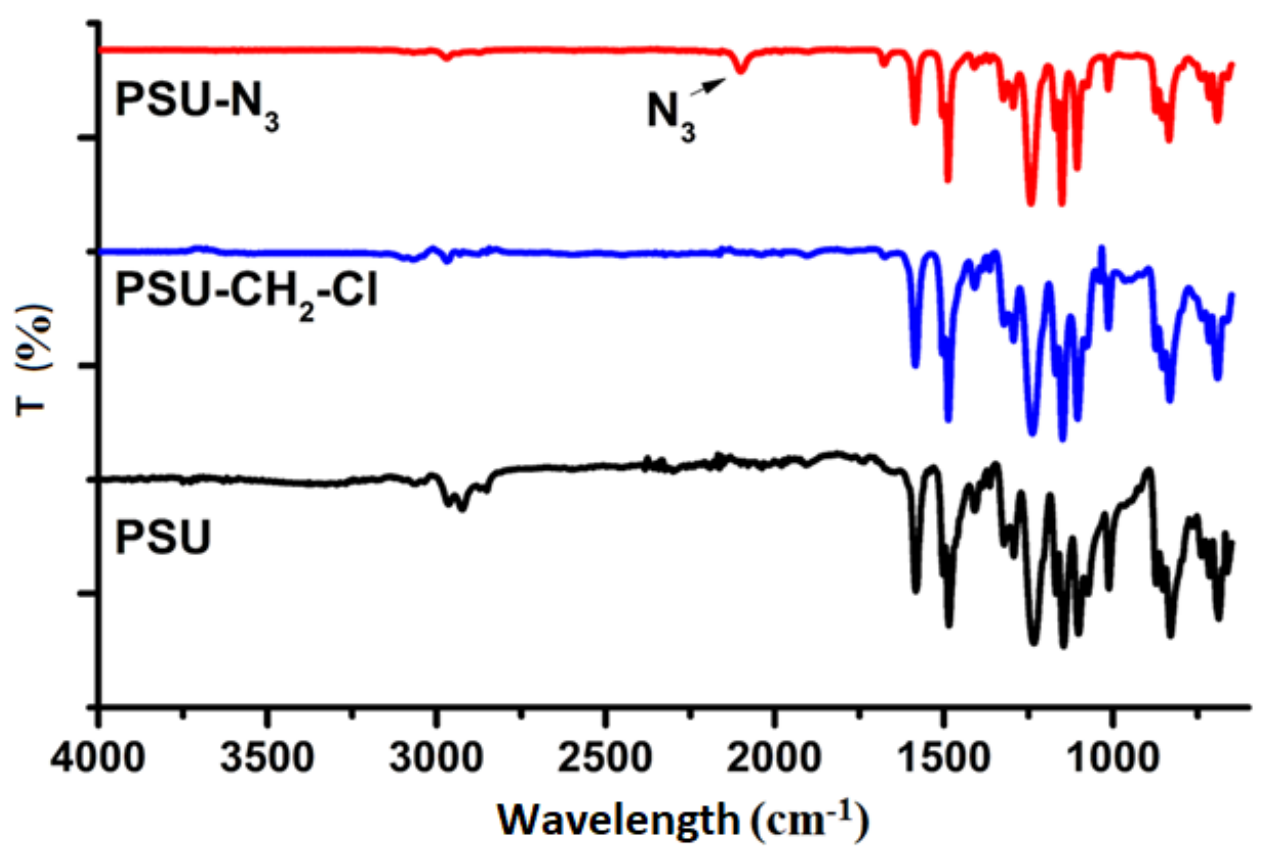

Figure 1. FT-IR spectra of neat, chloromethylated- and azide-functionalized polysulfones.

The successful transformation as well as the degree of substitution of chloromethyl group in PSU were determined by ${ }^{1} \mathrm{H}-\mathrm{NMR}$ measurement. As can be seen in Figure 2, six methyl protons (a) and two methylene protons (b) of PSU $-\mathrm{CH}_{2} \mathrm{Cl}$ appeared at 1.7 and $4.6 \mathrm{ppm}$, whereas four aromatic protons (c) were detected at $7.9 \mathrm{ppm}$. The degree of substitution of chloromethyl group into PSU backbone was calculated by using integral ratio of $b$ and $c$ protons and it was found as $7 \%$. 

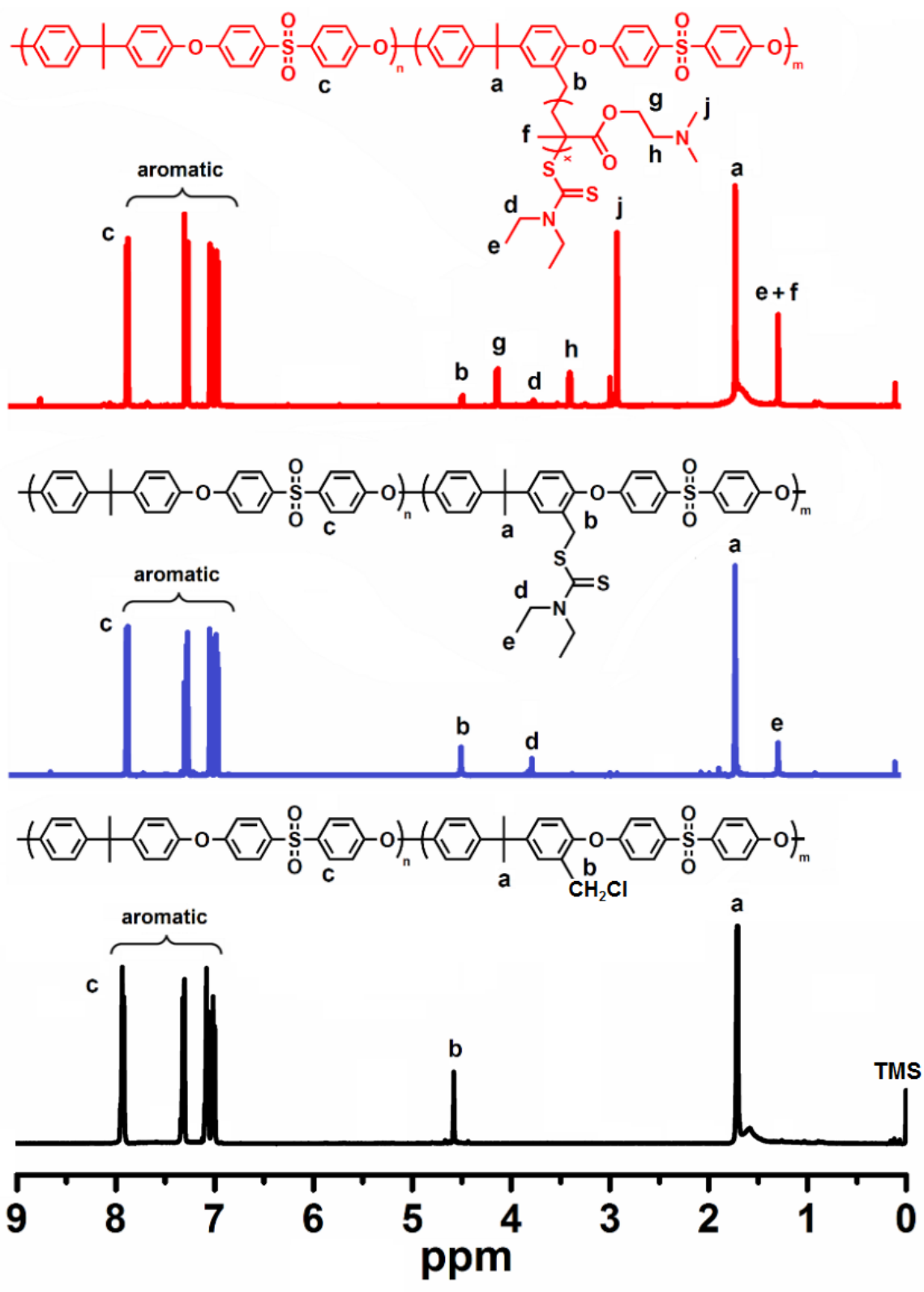

Figure 2. ${ }^{1} \mathrm{H}-\mathrm{NMR}$ spectra of PSU- $\mathrm{CH}_{2} \mathrm{Cl}, \mathrm{PSU}-\mathrm{DDC}$ and PSU-g-P DMAEMA.

In the second step, the macroiniferter (polysulfone containing diethyl dithiocarbamate) was prepared by nucleophilic substitution reaction of $\mathrm{PSU}-\mathrm{CH}_{2} \mathrm{Cl}$ and sodium diethyl dithiocarbamate according to Scheme 1 . The chemical structure of PSU-DDC was monitored by ${ }^{1} \mathrm{H}-\mathrm{NMR}$ spectroscopy. As can be seen in Figure 2, six methyl (e) and four methylene (d) protons of DDC moieties were 
observed at 1.3 and $3.8 \mathrm{ppm}$. In addition, the characteristic peaks of methyl (a), methylene (b) and aromatic protons (c) were observed at the same regions. These results clearly confirmed the successful transformation from PSU- $\mathrm{CH}_{2} \mathrm{Cl}$ to PSU-DDC.

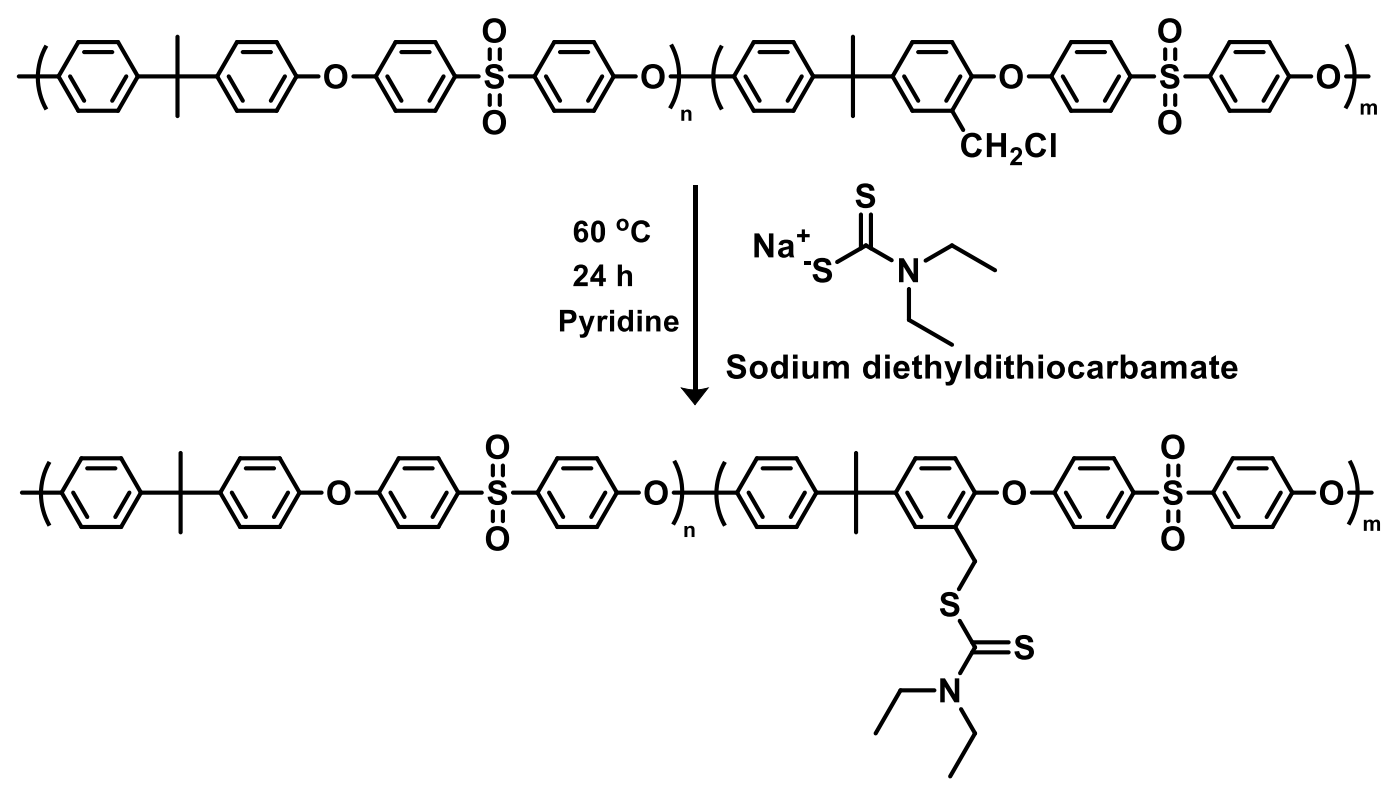

Scheme 1. The synthesis of macroiniferter agent (PSU-DDC).

Upon UV exposure, the PSU-DDC macroiniferter generated two types of radicals, an active radical on the PSU backbone and an inactive radical (DDC•). While the active macroradicals could initiate the polymerization of 2-(dimethylamino)ethyl methacrylate (PDMAEMA), the inactive radicals allowed to control the chain growth by eliminating unreversible termination reactions to obtain welldefined PSU-g-PDMAEMA graft copolymers (Scheme 2). 


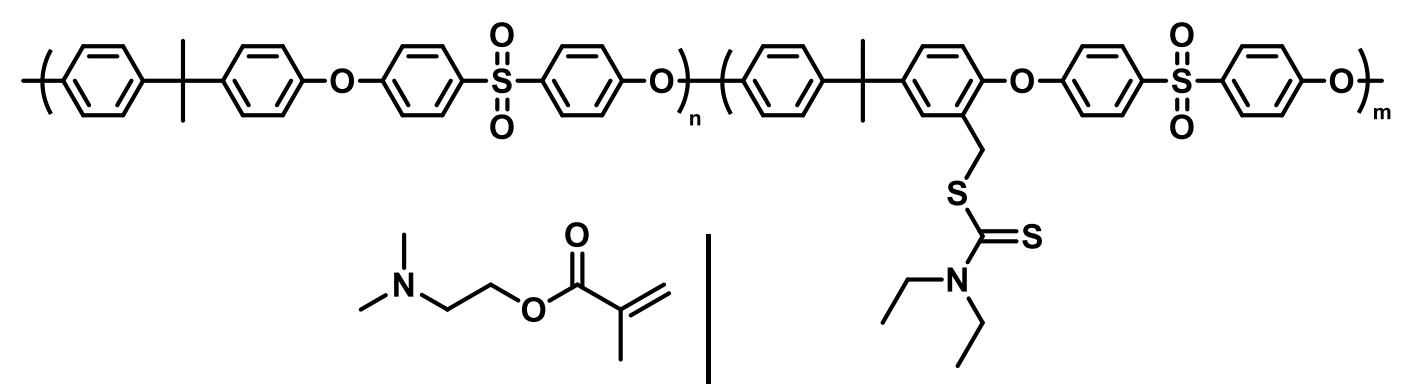

2-(dimethylamino)ethyl methacrylate

$300-400 \mathrm{~nm}, 24,48,72 \mathrm{~h}$

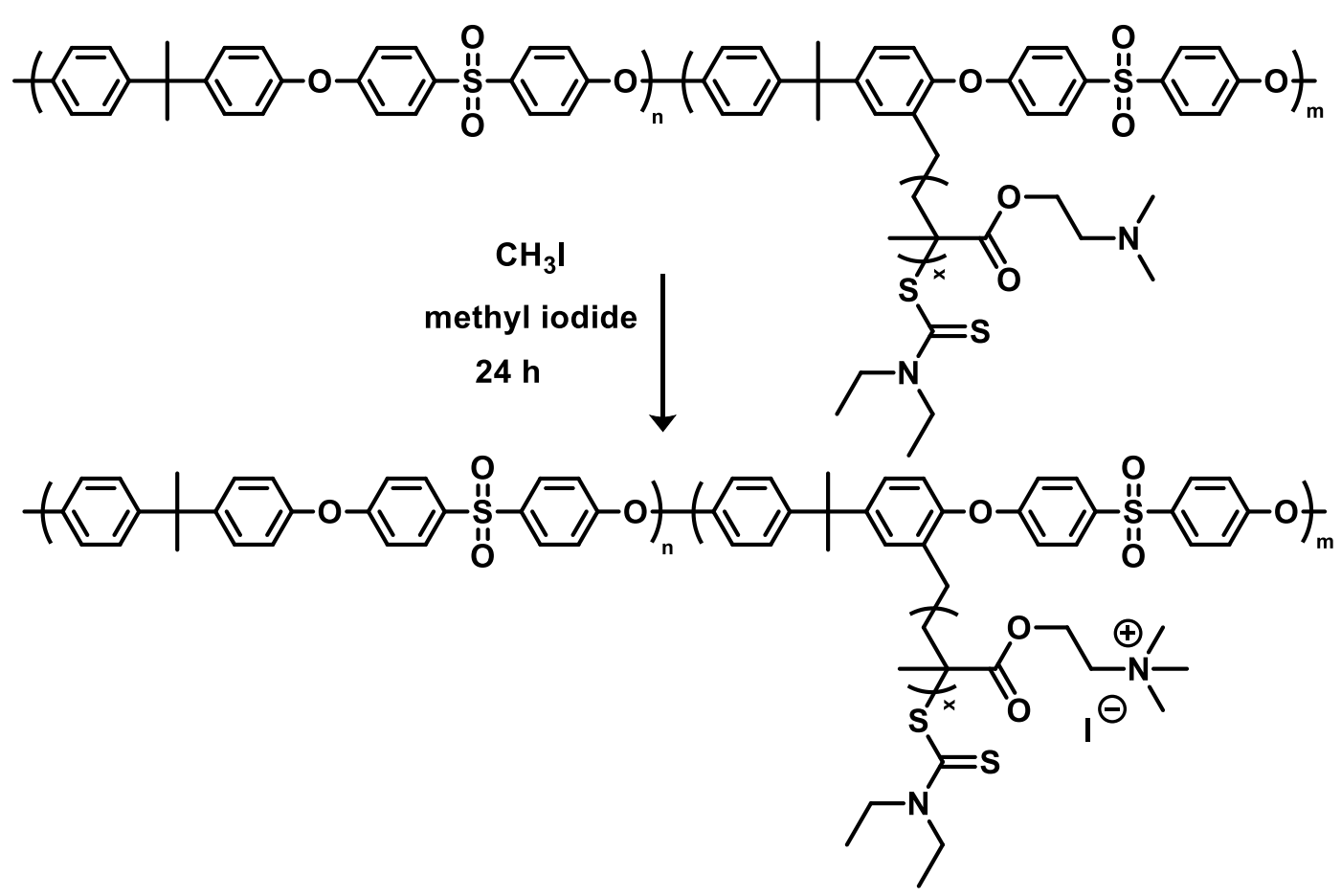

Scheme 2. The synthesis of PSU-g-PDMAEMA and PSU-g-QPDMAEMA.

By changing polymerization time, a series of graft copolymers was obtained and their structures were confirmed by FT-IR and ${ }^{1} \mathrm{H}-\mathrm{NMR}$ analyses. As shown in Figure 3, the characteristic ester peaks of $\mathrm{C}=\mathrm{O}$ and $\mathrm{C}-\mathrm{O}-\mathrm{C}$ of PDMAEMA were sharply observed at 1712 and $1100 \mathrm{~cm}^{-1}$, whereas the $\mathrm{N}(\mathrm{CH})_{3},-\mathrm{CH}$ and $\mathrm{C}-\mathrm{C}-\mathrm{N}$ bands were seen at 2825, 2775 and $1160 \mathrm{~cm}^{-1}$. In addition, the aromatic $\mathrm{C}=\mathrm{C}$ streching bands of PSU units were displayed at 1590 and $1485 \mathrm{~cm}^{-1}$. The graft copolymer structures were also investigated by ${ }^{1} \mathrm{H}-\mathrm{NMR}$ spectroscopy. Both the aliphatic (a) and aromatic (c) peaks belonging to protons of PSU backbone were clearly appeared at the same region. The new peaks assigned to aliphatic $(\mathrm{j}, \mathrm{h}, \mathrm{g}$ and $\mathrm{f})-\mathrm{CH}_{2}$ and $-\mathrm{CH}_{3}$ protons of PDMAEMA blocks appeared at 
2.9, 3.4, 4.1 and 1.5 ppm, respectively. Additionally, the methyl protons of DDC groups were still visible after graft copolymerization as shown in Figure 2.

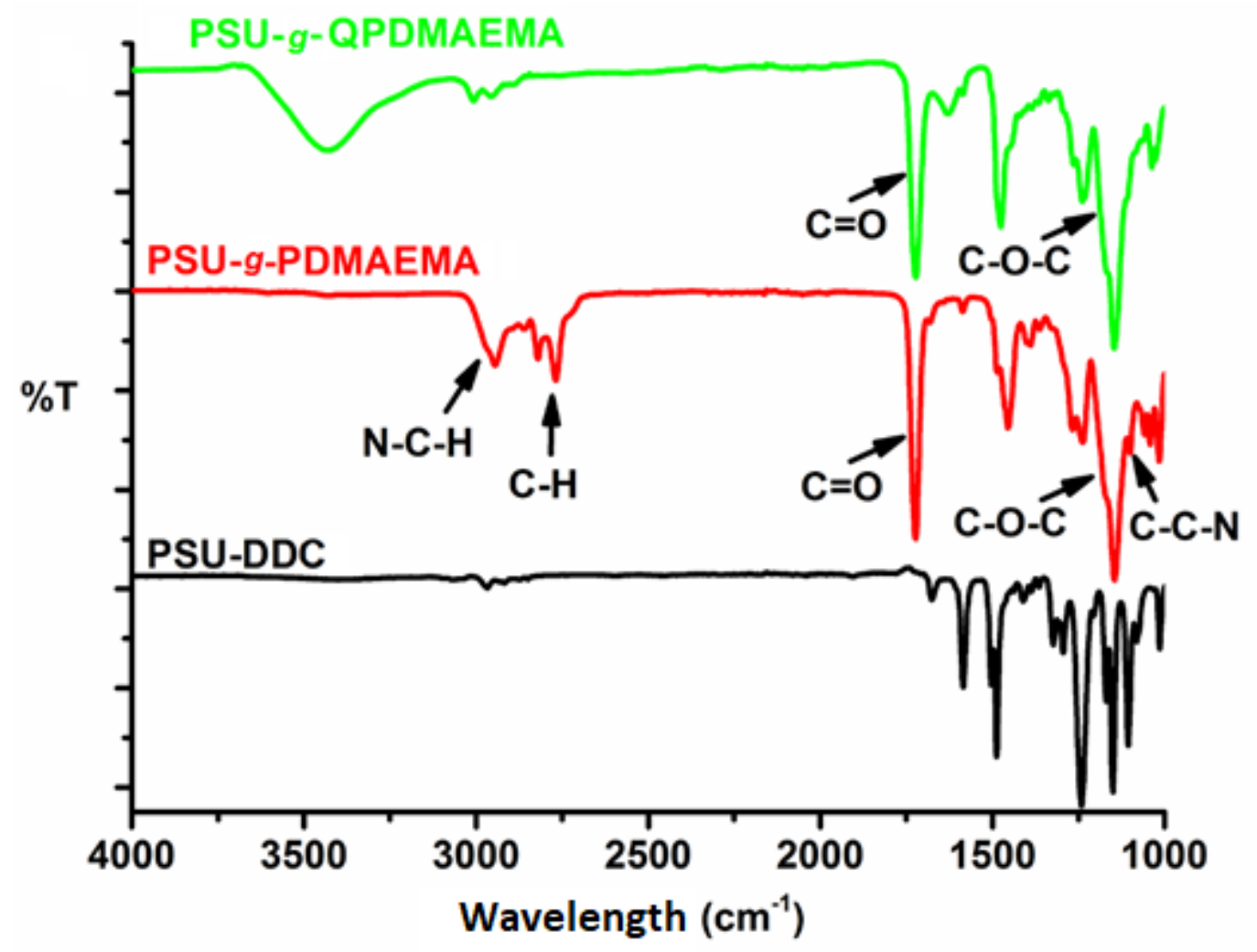

Figure 3. FT-IR spectra of PSU-DDC, PSU-g-PDMAEMA and PSU-g-QPDMAEMA.

The compositions of obtained graft copolymers were determined from the integration ratio of the protons ( $\mathbf{c}$ and $\mathbf{j}$ ) belonging to PSU and PDMAEMA blocks by using ${ }^{1} \mathrm{H}-\mathrm{NMR}$ spectroscopy. As a results, the conversions as well as the molecular weights of graft copolymers were gradually increased by increasing the polymerization time. In contrast, the composition of PSU segments in the graft copolymers were paralelly decreased from 68 to $35 \%$ (Table 1 ).

Molecular weight distributions of inital PSU and obtained graft copolymers were investigated by gel permeation chromatography. The peaks belonging to graft copolymers were shifted to lower retention times meaning higher molecular weights than neat PSU backbone. After $72 \mathrm{~h}$ grafting process, the molecular weight was shifted from $38.000 \mathrm{~g} / \mathrm{mol}$ to $121.000 \mathrm{~g} / \mathrm{mol}$ (Table 1). Furthermore, all graft samples displayed single GPC peak accompanied by relatively narrow molecular weight distributions below 2.10. This result implied that it was not admixed with an 
independently formed homopolymer. The single GPC peaks indicated that was no homopolymer contamination of graft copolymerization (Figure 4).

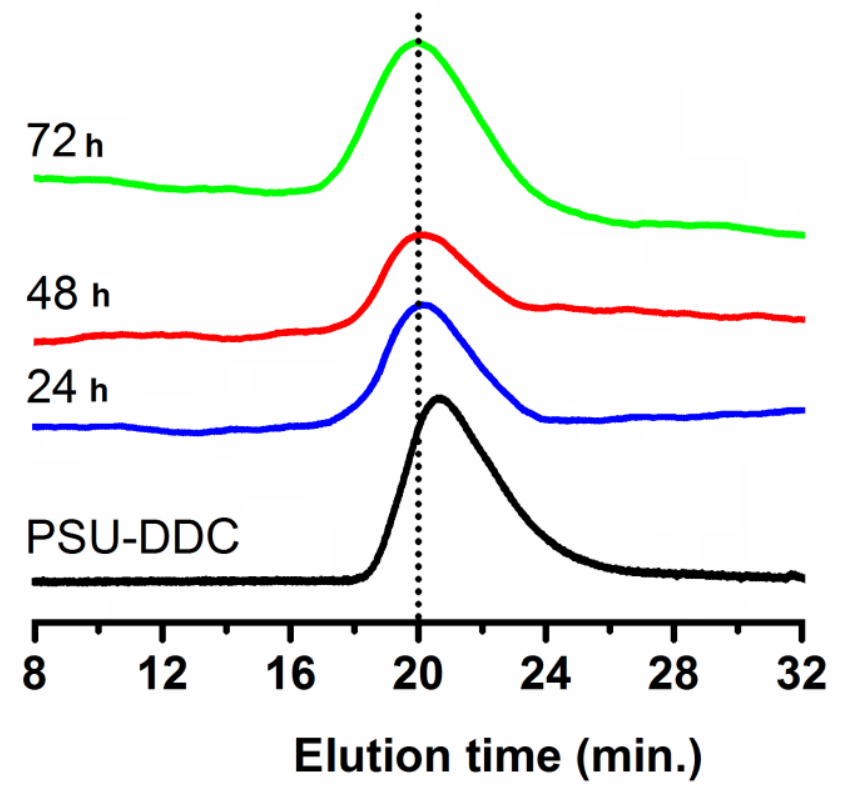

Figure 4. GPC curves of PSU-DDC and PSU-g-PDMAEMA polymers.

The thermal properties of resulting graft copolymers (PSU-g-PDMAEMA) were investigated by DSC analysis under nitrogen atmosphere and compared with initial PSU-DDC sample. According to DSC analysis, The PSU-DDC displayed a glass transition temperature $\left(T_{\mathrm{g}}\right)$ around $185^{\circ} \mathrm{C}$. The obtained graft copolymers were displayed only single $T_{\mathrm{g}}$ values at between 105 and $123^{\circ} \mathrm{C}$. In the literature, the $T_{\mathrm{gS}}$ of neat PSU and PDMAEMA were determined around 190 and $5{ }^{\circ} \mathrm{C}$, respectively. $(40,41)$ The $T_{\mathrm{gs}}$ of graft copolymers decreased from 123 to $105{ }^{\circ} \mathrm{C}$ by increasing composition of PDMAEMA segments (Table 1 ).

Table 1. The characterization results of PSU-DDc and PSU-g-PDMAEMA polymers.

\begin{tabular}{|c|c|c|c|c|c|c|c|}
\hline Polymer & $\begin{array}{c}\text { [Inf]/ } \\
{[\mathrm{M}]}\end{array}$ & $\begin{array}{c}\text { Time } \\
\text { (h) }\end{array}$ & $\begin{array}{c}M_{\mathrm{n}, \mathrm{GPC}} \\
(\mathrm{g} / \mathrm{mol})^{\mathrm{a}}\end{array}$ & $\begin{array}{l}M_{\mathrm{w}} / \\
M_{\mathrm{n}}{ }^{\mathrm{a}}\end{array}$ & $\begin{array}{l}\text { Yield } \\
(\%)^{b}\end{array}$ & $\begin{array}{r}\text { Comp. } \\
(\%)^{c}\end{array}$ & $\begin{array}{c}T_{g} \\
\left({ }^{\circ} \mathrm{C}\right)^{d}\end{array}$ \\
\hline PSU-DDC & - & - & 38.000 & 1.74 & 95 & 100 & 185 \\
\hline PSU-g-PDMAEMA-24 & $1 / 760$ & 24 & 53.000 & 1.58 & 47 & 68 & 123 \\
\hline PSU- $g$-PDMAEMA-48 & $1 / 760$ & 48 & 96.000 & 1.75 & 67 & 43 & 112 \\
\hline PSU-g-PDMAEMA-72 & $1 / 760$ & 72 & 121.000 & 2.10 & 98 & 35 & 105 \\
\hline
\end{tabular}


a) Determined by GPC, b) Calculated gravimetrically, ${ }^{\mathrm{c})}$ Determined by ${ }^{1} \mathrm{H}-\mathrm{NMR}$ spectroscopy from the intagration ratio of the protons ( $\mathbf{c}$ and $\mathbf{j}$ ), ${ }^{d}$ )Measured by DSC under nitrogen atmosphere.

After the successful grafting process, the tertiary amine groups in the graft copolymers were quaternized using methyl iodide to get corresponding quaternary ammonium salts containing graft copolymers (PSU-g-QPDMAEMA) (Scheme 2). Because of the solubility problems of quaternized graft copolymers, the ${ }^{1} \mathrm{H}-\mathrm{NMR}$ spectroscopy and GPC analysis were not performed. The quaternization process was only characterized by using FT-IR spectroscopy. The PSU-g-PDMAEMA displayed the characteristic $-\mathrm{N}(\mathrm{CH})_{3},-\mathrm{CH}$ and $\mathrm{C}-\mathrm{C}-\mathrm{N}$ bands at 2825, 2775 and $1160 \mathrm{~cm}^{-1}$, respectively. After quaternization process, the bands at 2825 and $2775 \mathrm{~cm}^{-1}$ of the PDMAEMA segments clearly disappeared. This result confirmed the successful formation of quaternary ammonium salts containing graft copolymers.

\section{CONCLUSIONS}

In conclusion, the PSU-based macroiniferter was successfully synthesized and applied for the polymerization of DMAEMA under mild conditions. This process allowed the successful synthesis of well-defined graft copolymers with high yields. The obtained graft copolymers displayed a single GPC peak with relatively narrow molecular weight distributions. The compositions of PDMEMA segments in the graft copolymers were gradually increased with increasing monomer conversion. All graft copolymers exhibited single $T_{\mathrm{g}}$ value at between 105 and $123^{\circ} \mathrm{C}$. After the successful synthesis of PSU-g-PDMAEMA, the tertiary amine groups in the side chains were readily converted to quaternary ammonium salts to obtain desired quaternary ammonium salts containing graft copolymers.

\section{ACKNOWLEDGEMENTS}

The authors to thank to Yalova University Research Fund for their financial support during this study (Project No: 2015/YL/053).

\section{REFERENCES}

1. Ioan S, editor. Functionalized polysulfones: synthesis, characterization, and applications: CRC Press; 2015 
October 23.

2. El-Hibri MJ, Weinberg SA. Polysulfones. Encyclopedia of Polymer Science and Technology: John Wiley \& Sons, Inc.; 2002 October 22.

3. Iojoiu C, Marechal M, Chabert F, Sanchez JY. Mastering sulfonation of aromatic polysulfones: Crucial for membranes for fuel cell application. Fuel Cells. 2005;5(3):344-54.

4. Abdelrasoul $\mathrm{A}$, Doan $\mathrm{H}$, Lohi $\mathrm{A}$, Cheng $\mathrm{CH}$. Morphology Control of Polysulfone Membranes in Filtration Processes: a Critical Review. Chembioeng Reviews. 2015;2(1):22-43.

5. Zhu LJ, Song HM, Wang JR, Xue LX. Polysulfone hemodiafiltration membranes with enhanced anti-fouling and hemocompatibility modified by poly(vinyl pyrrolidone) via in situ cross-linked polymerization. Materials Science \& Engineering C-Materials for Biological Applications. 2017;74:159-66.

6. Dizman C, Ates S, Uyar T, Tasdelen MA, Torun L, Yagci Y. Polysulfone/clay nanocomposites by in situ photoinduced crosslinking polymerization. Macromolecular Materials and Engineering. 2011;296(12):1101-6.

7. Dizman C, Uyar T, Tasdelen MA, Yagci Y. Synthesis and characterization of polysulfone/POSS hybrid networks by photoinduced crosslinking polymerization. Macromolecular Materials and Engineering. 2013;298(10):111723.

8. Yagci $Y$, Tasdelen MA. Mechanistic transformations involving living and controlled/living polymerization methods. Progress in Polymer Science. 2006;31(12):1133-70.

9. Dizman C, Tasdelen MA, Yagci Y. Recent advances in the preparation of functionalized polysulfones. Polymer International. 2013;62(7):991-1007.

10. Van der Bruggen B. Chemical Modification of Polyethersulfone Nanofiltration Membranes: A Review. Journal of Applied Polymer Science. 2009;114(1):630-42.

11. Yilmaz G, Toiserkani H, Demirkol DO, Sakarya S, Timur S, Torun L, et al. Polysulfone based amphiphilic graft copolymers by click chemistry as bioinert membranes. Materials Science and Engineering: C. 2011;31(5):1091-7.

12. Dizman C, Ates S, Torun L, Yagci Y. Synthesis, characterization and photoinduced curing of polysulfones with (meth) acrylate functionalities. Beilstein journal of organic chemistry. 2010;6.

13. Toiserkani H, Yilmaz G, Yagci Y, Torun L. Functionalization of polysulfones by click chemistry. Macromolecular Chemistry and Physics. 2010;211(22):2389-95.

14. Ates S, Dizman C, Aydogan B, Kiskan B, Torun L, Yagci Y. Synthesis, characterization and thermally activated curing of polysulfones with benzoxazine end groups. Polymer. 2011;52(7):1504-9.

15. Yilmaz G, Toiserkani H, Demirkol DO, Sakarya S, Timur S, Yagci Y, et al. Modification of polysulfones by click chemistry: amphiphilic graft copolymers and their protein adsorption and cell adhesion properties. Journal of Polymer Science Part A: Polymer Chemistry. 2011;49(1):110-7.

16. Dizman C, Altinkok C, Tasdelen MA. Synthesis of self-curable polysulfone containing pendant benzoxazine units via CuAAC click chemistry. Designed Monomers and Polymers. 2017;20(1):293-9.

17. Otsu T, Tazaki T. Living radical polymerization in homogeneous system with phenylazotriphenylmethane as a thermal iniferter. Polymer Bulletin. 1986;16(4):277-84. 
18. Otsu T, Yoshida M, Tazaki T. A model for living radical polymerization. Makromolekulare Chemie-Rapid Communications. 1982;3(2):133-40.

19. Tasdelen MA, Yagci Y. Chapter 3 Controlled/Living Radical Polymerization in the Presence of Iniferters. Fundamentals of Controlled/Living Radical Polymerization: The Royal Society of Chemistry; 2013. p. 78-111.

20. Lalevee J, Blanchard N, El-Roz M, Allonas X, Fouassier JP. New photoiniferters: Respective role of the initiating and persistent radicals. Macromolecules. 2008;41(7):2347-52.

21. Tasdelen MA, Durmaz YY, Karagoz B, Bicak N, Yagci Y. A new photoiniferter/RAFT agent for ambient temperature rapid and well-controlled radical polymerization. Journal of Polymer Science Part A: Polymer Chemistry. 2008;46(10):3387-95.

22. Tasdelen MA, Çiftci M, Uygun M, Yagci Y. Possibilities for photoinduced controlled radical polymerizations. Progress in controlled radical polymerization: mechanisms and techniques: ACS Publications; 2012. p. 59-72.

23. Vankerckhoven C, Vandenbroeck H, Smets G, Huybrechts J. Dithiocarbamate telechelic polymers synthesis and block copolymerization. Makromolekulare Chemie-Macromolecular Chemistry and Physics. 1991;192(1):101-14.

24. Tasdelen MA, Kahveci MU, Yagci Y. Telechelic polymers by living and controlled/living polymerization methods. Progress in Polymer Science. 2011;36(4):455-567.

25. Ishizu K, Ohta $Y$, Kawauchi S. Kinetics of hyperbranched polystyrenes by free radical polymerization of photofunctional inimer. Macromolecules. 2002;35(9):3781-4.

26. Joung YK, Choi JH, Bae JW, Park KD. Hyper-branched poly (poly (ethylene glycol) methacrylate)-grafted surfaces by photo-polymerization with iniferter for bioactive interfaces. Acta biomaterialia. 2008;4(4):960-6.

27. Watanabe J, Kano K, Akashi M. Bioconjugate polymer by photo-iniferter approach: Hydrophilic random or block copolymer-coated surface. Materials Science \& Engineering C-Materials for Biological Applications. 2009;29(7):2287-93.

28. Durmaz YY, Karagoz B, Bicak N, Yagci Y. Synthesis of block copolymers by combination of ATRP and photoiniferter processes. Polymer International. 2008;57(10):1182-7.

29. Cakmak I. Synthesis of multiblock copolymers via macroiniferter. European Polymer Journal. $1998 ; 34(10): 1561-3$.

30. Acar MH, Yagci Y. Studies on the block copolymerization of methacrylonitrile and hexafluorobutylmethacrlate using phenylazotriphenylmethane as thermal iniferter. Journal of Macromolecular Science-Chemistry. 1991;A28:177-83.

31. Temel BA, Amici J, Sangermano M, Yagci Y. Synthesis of H-shaped complex macromolecular structures by combination of atom transfer radical polymerization, photoinduced radical coupling, ring-opening polymerization, and iniferter processes. Journal of Polymer Science Part A: Polymer Chemistry. 2013;51(21):4601-7.

32. Kwak J, Lacroix-Desmazes P, Robin JJ, Boutevin B, Torres N. Synthesis of mono functional carboxylic acid poly(methyl methacrylate) in aqueous medium using sur-iniferter. Application to the synthesis of graft copolymers polyethylene-g-poly(methyl methacrylate) and the compatibilization of LDPE/PVDF blends. Polymer. 2003;44(18):5119-30.

33. Pan X, Tasdelen MA, Laun J, Junkers T, Yagci Y, Matyjaszewski K. Photomediated controlled radical 
polymerization. Progress in Polymer Science. 2016;62:73-125.

34. Tasdelen MA, Yagci Y. Photochemical methods for the preparation of complex linear and cross-linked macromolecular structures. Australian Journal of Chemistry. 2011;64(8):982-91.

35. Al-Kaabi K, van Reenen AJ. Controlled radical polymerization of poly (methyl methacrylate-gepichlorohydrin) using $\mathrm{N}, \mathrm{N}$-dithiocarbamate-mediated iniferters. Journal of applied polymer science. 2008;108(4):2528-34.

36. Gacal B, Durmaz H, Tasdelen M, Hizal G, Tunca U, Yagci Y, et al. Anthracene-maleimide-based Diels-Alder" click chemistry" as a novel route to graft copolymers. Macromolecules. 2006;39(16):5330-6.

37. Demirci G, Tasdelen MA. Synthesis and characterization of graft copolymers by photoinduced CuAAC click chemistry. European Polymer Journal. 2015;66:282-9.

38. Tasdelen MA, Yagci Y, Demirel AL, Biedron T, Kubisa P. Synthesis and Characterization of Block-Graft Copolymers [poly (epichlorohydrin-b-styrene)-g-poly (methyl methacrylate)] by Combination of Activated Monomer Polymerization, NMP and ATRP. Polymer bulletin. 2007;58(4):653-63.

39. Tasdelen MA, Moszner N, Yagci Y. The use of poly (ethylene oxide) as hydrogen donor in type II photoinitiated free radical polymerization. Polymer bulletin. 2009;63(2):173-83.

40. Ates S, Tatar-Guner P, Yagci Y, Levent Demirel A. Synthesis and characterization of polysulfone-g-poly (2alkyl-2-oxazoline) s. Designed Monomers and Polymers. 2013;16(2):137-44.

41. Goracci G, Arbe A, Alegría A, García Sakai V, Rudić S, Schneider GJ, et al. Influence of Solvent on Poly(2(Dimethylamino)Ethyl Methacrylate) Dynamics in Polymer-Concentrated Mixtures: A Combined Neutron Scattering, Dielectric Spectroscopy, and Calorimetric Study. Macromolecules. 2015;48(18):6724-35. 
Oran and Tasdelen. JOTCSA. 2018; 5(1): 117-132.

RESEARCH ARTICLE 